\title{
TITLE:
}

\section{$<$ Note> Use of wet hair to capture swarming termites by a chimpanzee in Mahale, Tanzania}

\section{$\operatorname{AUTHOR}(\mathrm{S}):$}

Kiyono-Fuse, Mieko

\section{CITATION:}

Kiyono-Fuse, Mieko. < Note> Use of wet hair to capture swarming

termites by a chimpanzee in Mahale, Tanzania. Pan Africa News 2008, 15(1): 8-12

\section{ISSUE DATE:}

2008-06

URL:

http://hdl.handle.net/2433/143487

\section{RIGHT:}

Copyright (C) Pan Africa News. 
<NOTE $>$

Use of wet hair to capture swarming termites by a chimpanzee in Mahale, Tanzania

Mieko Kiyono-Fuse

Graduate School of Science, Kyoto University, Japan

\section{INTRODUCTION}

Chimpanzees of all well-studied groups are known to eat termites to some extent. Each group differs in how 
and which species they prey upon. For example, chimpanzees of some groups eat the termite of the genus Macrotermes using fishing tools ${ }^{1,2,3,4}$, whereas chimpanzees of other groups eat other termite species without using tools ${ }^{5}$. In the Mahale Mountains National Park, members of the $\mathrm{B}$ group use tools, but those of the $\mathrm{K}$ and $\mathrm{M}$ groups very rarely do so ${ }^{6,7,8,9}$. Two methods of direct termite capturing behaviors have been observed among the chimpanzees of the $\mathrm{K}$ and $\mathrm{M}$ groups ${ }^{9}$. One is destroying the tower of a termite mound and picking up the termites that come out. This behavior is observed frequently in the late rainy season when reproductively active termites (alates) gather in towers made on the ground. The second is feeding on alates that swarm in the air. This behavior is observed at the end of the rainy season on days when winged termites fly from their nests, forming a vast swarm and swirling around the tops of trees. Among the termite species living in this area ${ }^{9}$, only Pseudacanthotermes exhibits this unique behavior. Uehara $^{9}$ pointed out that this characteristic behavior of the genus Pseudacanthotermes clearly influenced the chimpanzee's feeding techniques, but he did not give a detailed analysis.

The previously unobserved behavior of a female chimpanzee capturing termite alates from a vast swarm by sticking them to wet hair on her body is described.

\section{METHODS}

I studied $\mathrm{M}$ group chimpanzees, which have been subjects of long-term research since $1965^{10}$, from July to August in 2006 and from October of 2006 to May of 2007. The $\mathrm{M}$ group consisted of about 60 individuals during the study period. The following observation was made during the study and was videotaped.

In the video analysis, I counted the number of termites eaten and categorized the chimpanzee's feeding methods into the following three.

Wet hair-use: picking up alates that stick to the wet hair of the arm or the body.

Grabbing: extending an arm or arms into the air and catching alates with the palm(s)
Gathering from leaves: picking up alates attached to leaves.

I also counted the number of times she swung her arms per minute.

\section{OBSERVATIONS}

On April 13, 2007, it was raining all day long. The rainfall that day was $33.1 \mathrm{~mm}$. At 12:30, I began to follow a party consisting of six females including FT (c. 40 years old) and her two daughters FV (8 years old) and FM (4 years old). They walked through the bush for a while and encountered termites flying here and there at 17:17. They found a spot on the ground where the termites were concentrated, and picked termites off the ground and ate them. They stopped eating termites and then they arrived at a Parinari curatellifolia tree at 17:57, climbed up it and started eating its fruits. At 18:01, FT climbed down the tree and moved away. Since only FT began showing an unusual behavior, I decided to focus my attention on her.

\section{The flow of action that FT carried out from 18:02 to 18:22}

FT was gathering termites from leaves on the tree in which the other individuals were (Phase 1). She started climbing a higher tree that was standing next to the first one (Phase 2). She ate the termites sticking to the wet hair of her own body as soon as she reached the treetop. She stood up and began to extend her arm and grab termites in the air at an open spot in the treetop. She extended her arm behind her body, vigorously swung it over and over again in wide arcs with the elbow straightened, and finally brought the palm to her mouth. The motion was similar to swinging a table tennis racket. She alternated arms repeatedly (Phase 3). The behavior of swinging her arm and eating the termites attached to it was repeated (Phase 4). She sat in a fork of this tree. Sometimes she gathered termites from leaves. Many termites were still swarming in the air (Phase 5). She moved to another open spot and started to reach out her arm. She reached and swung with both hands at the same time in this phase only (Phase 6). She moved back to the spot she had used 


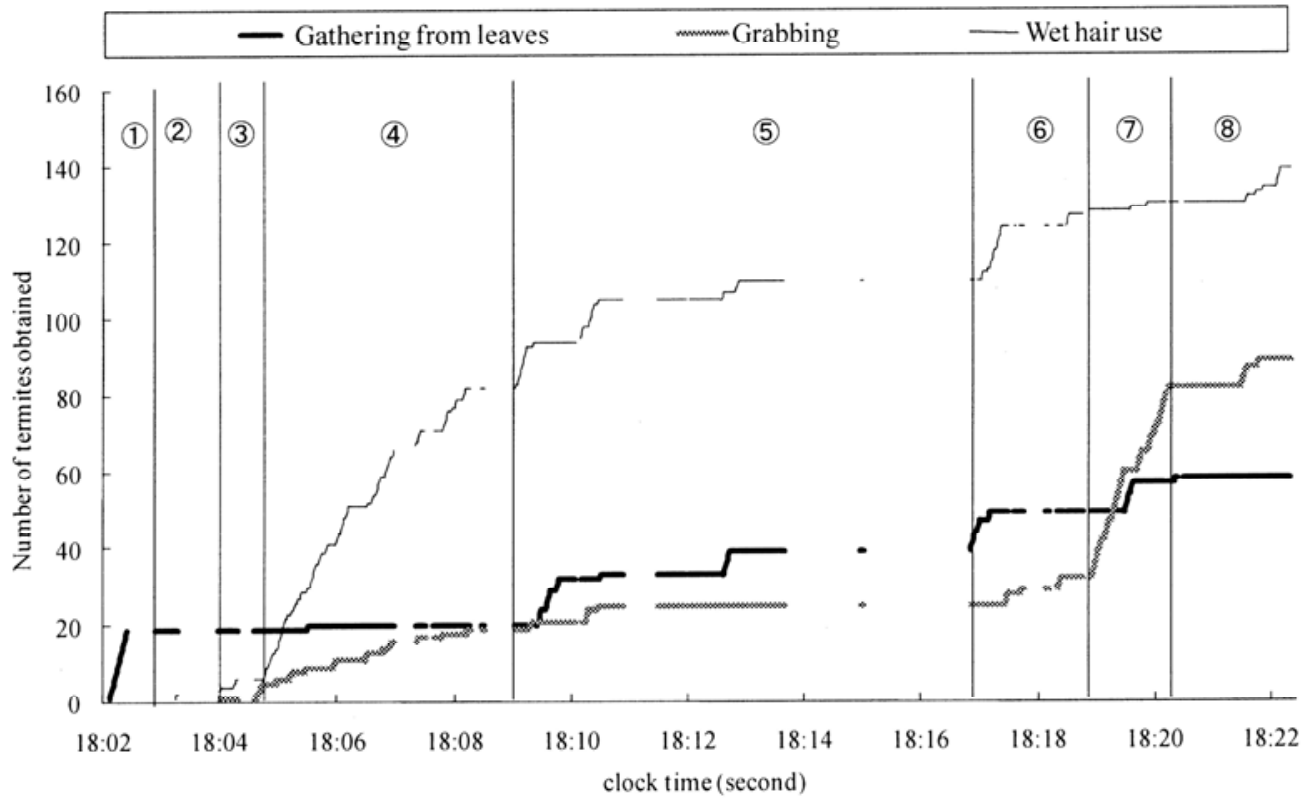

Fig. 1. The accumulated number of termites obtained by FT. The different lines show different methods of obtaining termites. The blank portions mean that FT's behavior could not be observed well due to the cover of leaves and/or a branch. The circled number corresponds with the phase number mentioned in the text.

in Phases 3 and 4. She was eating termites grabbed by her palm although the arm-swinging movement continued as before (Phase 7). She did not swing her arm again until after she climbed down. The number of termites swarming in the air was fewer than at the beginning (Phase 8).

\section{The number of termites obtained}

Figure 1 shows the accumulated number of termites FT obtained during this sequence. In phase 4 , the number of termites caught with wet hair use increased rapidly. The number of termites caught by grabbing increased rapidly in phase 7 , but the number of times she swung her arms did not differ significantly between phases 4 and 7 (Fig. 2). The number of termites caught by gathering from leaves increased gradually compared to the other two methods. In total, FT obtained the largest number of termites by wet hair use.

\section{Behaviors of other individuals}

FT's infant FM who was traveling independently reached out her arm at the same place as FT at 18:15. FM extended her hand but did not catch or eat any termites. Except for this, the other individuals in the vicinity of FT were only gathering from leaves at several places on the tree and did not employ wet hair use as did FT.

\section{DISCUSSION}

What factors influence FT's catching behavior? FT obviously ate more termites by wet hair use than by grabbing. In order to use wet hair, some environmental conditions might have been important. One is that her body was wet from the beginning until the end of this behavior. Second is that Pseudacanthotermes has relatively long wings (personal observation). The wing size is as long as that of the genus Macrotermes, which has the largest wing size in Africa ${ }^{11}$. In addition, termite reproductive activity may have influenced her behavior. The flight of the termites for copulation lasted about twenty minutes in this case. Both the number of times she swung her arms and the number of termites caught by grabbing also increased toward the end of the feeding behavior. On the other hand, the number caught with wet 




Fig. 2. The number of times FT swung her arm per minute.

hair use decreased. It is likely that the number of alates in the air decreased as the copulation finished gradually toward the end. One possibility is that the decrease in wet hair use may have been due to the decrease in the number of termites flying in the air. Another possibility is that the increase in grabbing may have been caused by her improved skill at the end. To examine both hypotheses requires more observation of similar behavior in the future.

The behavior of capturing swarming termites occurred not only in the $\mathrm{K}$ group but also in the $\mathrm{M}$ group. FT emigrated from an unknown group to the K group and then immigrated again to the $M$ group in $1973^{12}$. It is unknown whether the wet-hair-use technique was common in the K group or whether FT learned it by trial and error. The vast swarming of Pseudacanthotermes is an annual event. Even though the period is consistent and seasonal, its frequency is low and the durations of the termites' copulation flights are short. Therefore, it is likely that this time-limited capturing technique could be observed employed by some other individuals besides FT at the same season of another year. Finally, researchers should be cautious not to simply conclude that the feeding technique reported here is cultural, considering the seasonal rarity of observation chances whether at
Mahale or at other sites.

Acknowledgments. I thank the Tanzania Commission for Science and Technology, the Tanzania Wildlife Research Centre, and the Tanzania National Parks for permission to do the field research, and Mahale Mountains National Park and Mahale Wildlife Research Centre for logistic support. My gratitude goes to trackers who assisted my work in the forest. I thank Dr. T. Nishida, Dr. M. Nakamura and members of Lab. Human Evolution Studies for support of this research and comments on this note. Field research was conducted under the JSPS Grant-in-Aid for Basic Scientific Research (\#16255007 \& 19255008to T. Nishida).

\section{REFERENCES}

1 McGrew WC 1992. Chimpanzee Material Culture. Cambridge University Press, Cambridge.

2 Sanz C, Morgan D, Gulick S 2004. New insights into chimpanzees, tools, and termites from the Congo Basin. Am Nat 164:567-81.

3 McGrew WC, Pruetz JD, Fulton SJ 2005. Chimpanzees use tools to harvest social insects at Fongoli, Senegal. Folia Primatol 76:222-6.

4 Tutin CEG, Ham R, Wrogemann D 1995. Tool-use by chimpanzees (Pan t. troglodytes) in the Lopé Reserve, Gabon. Primates 36:181-192. 
5 Reynolds V 2005. The Chimpanzees of the Budongo Forest: Ecology, Behaviour, and Conservation. Oxford University Press, Oxford, pp. 54-84.

6 McGrew WC, Collins DA 1985. Tool use by wild chimpanzees (Pan troglodytes) to obtain termites (Macrotermes herus) in the Mahale Mountains, Tanzania. Am J Primatol 9:47-62.

7 Nishida T, Uehara S 1980. Chimpanzees, tools, and termites: another example from Tanzania. Curr Anthropol 21: 671-673.

8 Takahata Y 1982. Termite-fishing observed in the M group chimpanzees. Mahale Mountains Chimpanzee Research Project, Ecological Report No.18.

9 Uehara S 1982. Seasonal changes in the techniques employed by wild chimpanzees in the Mahale Mountains, Tanzania, to feed on termites (Pseudacanthotermes spiniger). Folia Primatol 37: 44-76.

10 Nishida $\mathrm{T}$ 1990. The Chimpanzees of the Mahale Mountains. University of Tokyo Press, Tokyo.

11 Harris WV 1961. Termites: Their Recognition and Control. Longmans, London.

12 Nishida T, Corp N, Hamai M et al. 2003. Demography, female life history, and reproductive profiles among the chimpanzees of Mahale. Am J Primatol 59: 99-121. 